УДК 32 (327)

ШЕРЕМЕТЬЕВ Денис Витальевич - аспирант Института Европы РАН(125009, Россия, г. Москва, ул. Моховая, 11, стр. 3); старший преподаватель кафедры управления, сервиса и туризма Института международных социально-гуманитарных связей (123100, Россия, г. Москва, ул. АнтоноваОвсеенко, 6, cmp. 1; den.sheremetiev@yandex.ru)

\title{
МЕГАТРЕНДЫ РАЗВИТИЯ СОВРЕМЕННОЙ МИРОСИСТЕМЫ И ИНТЕРЕСЫ БЕЗОПАСНОСТИ РОССИИ
}

Аннотация. В статье исследуются основные характеристики формирующейся новой системы международных отношений, выделяются мегатренды, определяющие ее становление. Автор отмечает, что, хотя влияние США на мировые политические и экономические процессы уменьшается, они по-прежнему остаются системообразующим фактором мировой политики и мировой экономики и сохранят эти позиции на обозримую перспективу. Мировая политика реализуется в условиях глобализации, которая остается основным мегатрендом развития современного мира. Возникшее противоречие между объективной потребностью в глобальном управлении и невозможностью его осуществления также представляет собой один из важнейших мегатрендов современности, определяющих ход мирового политического процесса.

Для России очень важно вписаться в эти мегатренды, найти в них свою нишу и использовать их в интересах собственной модернизации, с тем чтобы избежать маргинализации.

Ключевые слова: мегатренды, глобализация, трансрегионализация, сила, право, глобальное управление, моноцентричность, полицентричность, суверенитет, биполярность

\footnotetext{
Сегодняшняя «холодная война» между Россией и Западом представляет собой одну из важнейших характеристик современных международных отношений, под влиянием которой формируется новый мировой порядок. Ее возникновение не является случайностью или стечением исторических обстоятельств, а стало результатом системных противоречий между этими двумя историческими антагонистами, которые накапливались в течение всего периода существования новой России. Наиболее отчетливо антагонизм между Россией и Западом проявился в ходе украинского и сирийского кризисов, которые выявили всю глубину недоверия друг к другу и несовместимость их геополитических интересов.

Прошло более четверти века с тех пор, как распался Советский Союз. За это время вся система международных отношений претерпела серьезные изменения. В целом она по-прежнему моноцентрична, т.к. ее главным системообразующим элементом являются США, которые оказывают огромное влияние на всю структуру международных политических и экономических отношений. Конечно, влияние Вашингтона в мире в абсолютном выражении постепенно сокращается, но в относительном оно по-прежнему еще очень велико и таковым останется на обозримую историческую перспективу. США не утратили способности к динамичному экономическому развитию на основе современных технологий, о чем свидетельствуют темпы роста американского ВВП. Политика Трампа направлена на придание динамизма американской экономике, сохранение лидерства США в мире, что не вызывает отторжения у большинства стран мира. Политическая и бизнес-элита Соединенных Штатов не намерена отказываться от лидирующих позиций и готова использовать все имеющиеся у нее ресурсы для их сохранения.
}

Сегодня в мире имеются две страны, которые бросили вызов американской 
гегемонии и добиваются переформатирования мирового порядка в сторону учета своих интересов. Это Китай и Россия.

Китайское руководство концентрирует усилия в первую очередь на решении проблем внутреннего развития и подчиняет китайскую внешнюю политику интересам своей внутренней политики. Поэтому оно сдержанно относилось к участию в управлении глобальными и региональными процессами, особенно кризисными. Однако по мере возрастания мощи Китай начинает добиваться переустройства международных отношений с учетом собственных интересов. Заявку на проведение такой политики Пекин сделал на состоявшемся в октябре 2017 г. XIX съезде КПК, но он намерен делать это с помощью не силовых, а в первую очередь экономических инструментов, эффективного применения «мягкой силы».

Современный Китай, наряду с США и ЕС, представляет собой системообразующий фактор современных мировых экономических отношений. Политика глобализации, инициированная Западом, пошла ему явно на пользу. Он превратился в экспортоориентированную страну с гигантским потенциалом и огромным профицитом внешней торговли. Сегодняшний Китай в состоянии предлагать миру стратегические проекты стоимостью в сотни миллиардов долларов, рассчитанные на реализацию в течение многих лет и ориентированные на привлечение к их осуществлению десятков стран. Их политический истеблишмент, бизнес-элита готовы поддержать Пекин в начинаниях, которые способны принципиальным образом изменить мировой геостратегический и геополитический ландшафт. Таковым является предложенный Пекином экономический проект «Один пояс - один путь».

КНР выступает в качестве мощного конкурента США и ЕС, медленно, но уверенно тесня Запад на мировых рынках. США в качестве средства борьбы с торгово-экономической экспансией Китая решили использовать политику протекционизма. В ответ Пекин пообещал сделать то же самое. Смогут ли две сверхдержавы договориться между собой и не допустить развязывания торговой войны или же сорвутся в пропасть противостояния с непредсказуемыми последствиями? В зависимости от ответа на этот вопрос будет определяться будущее мировых экономических и, соответственно, политических отношений. Обе державы тесно связаны экономически и в случае открытой конфронтации и, тем более, вооруженного столкновения обоюдно могут потерять очень многое. Обе страны уже начали борьбу за переустройство мира, за мировое лидерство, но при этом ищут возможности избегать взаимной конфронтации и договариваться друг с другом. Об этом свидетельствуют переговоры президента США Д. Трампа и председателя КНР Си Циньпина, которые состоялись 1 декабря 2018 г. во время саммита «Большой двадцатки» в Буэнос-Айресе. Американский президент сделал шаг назад в своей конфронтационной политике в отношении Китая, отказавшись от запланированного на 1 января 2019 г. повышения тарифов на китайскую продукцию в обмен на покупку Пекином очень значительного количества американских сельскохозяйственных, энергетических и промышленных товаров. Сегодня трудно сказать, будут ли эти договоренности реализованы, но совершенно очевидно желание обеих сторон, и в первую очередь Китая, идти на взаимные уступки и договариваться ${ }^{1}$.

Отношение Вашингтона к быстро возвышающемуся Китаю двойственное: с одной стороны, он рассматривается как конкурент, затрудняющий реализа-

1 The Washington Post: после «чрезвычайно успешной встречи» США и Китай условились провести новые переговоры и воздержаться от повышения тарифов в течение 90 дней. Доступ: https:// inosmi.ru/politic/20181202/244141146.html?utm_refferes=https\%3A\%2F\%2Fzen.yandex.com (проверено 03.12.2018). 
цию американских претензий на доминирование в мире, а с другой - там очень хорошо понимают, что противостояние с Пекином, учитывая его ресурсы, потребует от США огромных усилий и его перспективы весьма неопределенны. Поэтому реалистически мыслящая часть американского политического истеблишмента и бизнес-сообщества выступает за сотрудничество на взаимовыгодной основе. По словам Г. Киссинджера, «США и Китаю крайне необходимо работать вместе, чтобы поднять уровень наших взаимоотношений от прагматизма и решения повседневных проблем... Наша задача - найти способ сопряжения американской исключительности и “китайской мечты", что позволит создать новый мировой порядок на благо всех»1.

В свою очередь и Китай демонстрирует готовность к сотрудничеству с Вашингтоном, рассматривая его как долгосрочный проект «китайской мечты». Об этом свидетельствует активная покупка Китаем американских долговых облигаций, которые уже сейчас оцениваются на сумму в 1,146 трлн долл. Тем самым он финансирует американскую экономику в больших масштабах 2 . Возможно ли формирование «Большой двойки» в составе США и Китая, образование которой инициировалось еще Бараком Обамой [Brzezinski 2009]? Тогда в КНР к этой идее отнеслись прохладно, резонно полагая, что Вашингтон не будет рассматривать Пекин в качестве равноправного партнера, и заявили о своей приверженности концепции многополярного мира. Но за прошедшие годы ситуация для Китая принципиальным образом изменилась. Он стал главным торговым партнером более чем 100 стран мира. Китайская экономика по паритету покупательной способности уверенно опережает американскую. Китайский юань с осени 2017 г. вошел в число резервных валют мира. В этих условиях китайские лидеры полагают, что теперь можно и побороться за равноправные отношения с США, на равных с ними управлять миром. Готова ли на это пойти американская политическая и финансовая элита, бизнес-круги пока что не ясно. Но в зависимости от ответа на этот вопрос будет определяться вся архитектура международной безопасности, обрисовываться силовые поля в международных отношениях.

Китайские политологи не исключают и возможности возникновения конфликта между США и Китаем вследствие столкновения их геополитических и геоэкономических интересов. В этой связи отмечается, что «у поднимающихся держав, входящих в мировую систему... существует проблема необходимости определения заново правил, в выработке которых они не участвовали и которые не соответствуют их интересам. Поэтому в процессе стремительного осуществления Китаем модернизации теоретически есть проблема существования потенциального противника, возможность противостояния и конфронтации с Соединенными Штатами» [Кузык, Титаренко 2006: 553-554].

США в своем стремлении сохранить глобальное лидерство рассматривают Китай как главный в исторической перспективе вызов, угрожающий подорвать позиции страны в мире. Долгосрочная стратегия Вашингтона в отношении Пекина строится на основе доктрины «окружения» и стратегического сдерживания. Как отмечается в Стратегии национальной безопасности США, одобренной президентом Бараком Обамой в феврале 2015 г., «Соединенные Штаты приветствуют укрепление стабильного, мирного и процветающего Китая. Мы стремимся к развитию конструктивных отношений с Китаем, ...к сотрудничеству в решении общих региональных и глобальных вопросов... Хотя конку-

1 Пекин начал дрейф в сторону Америки. - Военное обозрение. 02.10.2017. Доступ: https://topwar. ru/126247-pekin-nachal-dreyf-v-storonu-ameriki.html (проверено 15.01.2019). .

2 Там же. 
ренция будет обязательно, мы не верим в неизбежность конфронтации. В то же время конкуренцией мы будем заниматься с позиции силы, настаивая на том, чтобы Китай соблюдал международные нормы и правила в самых разных вопросах» 1 . В Стратегии национальной безопасности, одобренной Д. Трампом в декабре 2017 г., содержится уже более жесткая оценка политики КНР в мире, и особенно в Азиатско-Тихоокеанском регионе. В документе прямо говорится, что «Китай представляет и вызов, и угрозу интересам США, а его действия в Южно-Китайском море представляют угрозу суверенитету других народов и подрывают региональную стабильность». По оценке, содержащейся в документе, военное строительство в Китае ограничивает доступ США в регион и обеспечивает Пекину свободу рук ${ }^{2}$.

Такая радикализация заявлений Вашингтона связана с тем, что КНР превратилась в независимый от Запада источник ресурсов для третьих стран и колоссальный рынок. За декларациями китайских руководителей о «сообществе общей судьбы», «одном поясе - одном пути» стоят огромные деньги, позволяющие Китаю развиваться самостоятельно и игнорировать мнение Вашингтона.

Китайские деньги представляют собой прямой и непосредственный вызов для интересов США стратегического характера. В Америке осознали, что Китай не будет играть роль удобного младшего партнера и, более того, он будет способствовать повышению степени относительной самостоятельности других государств, подрывая тем самым американские претензии на мировое господство.

Политика сдерживания, проводимая коллективным Западом во главе с США в отношении России и Китая, ставят наши страны по одну сторону баррикад. Логика противостояния постепенно трансформирует российско-китайские взаимоотношения из состояния стратегического партнерства в союзнические. Главная задача сейчас заключается в том, чтобы подвести под прочные политические отношения двух стран солидный экономический фундамент. Заметная радикализация американской внешней политики при президенте Д. Трампе не оставляет Москве и Пекину другого выбора, чтобы сохранить свою международную субъектность.

Сегодня у Китая и России нет столкновения геополитических или геоэкономических интересов, что способствует укреплению их стратегического взаимодействия. И хотя на Западе предполагали, что широкомасштабная китайская стратегическая программа «Один пояс - один путь», ориентированная в т.ч. и на проникновение в страны Центральной Азии, неизбежно приведет к столкновению с Россией в борьбе за влияние, этого не произошло. Россия спокойно реагирует на рост китайских инвестиций в постсоветских государствах, т.к. действия Китая в них не направлены на ликвидацию существующих политических режимов и на приведение к власти антироссийски настроенных политических сил.

Ожесточенная борьба за переустройство мирового порядка, развернувшаяся между коллективным Западом, с одной стороны, и Россией и Китаем - с другой, происходит в условиях глобализации.

Являясь еще одни важнейшим мегатрендом современного мирового развития, глобализация представляет собой результат трансформации мировых производительных сил, которые не могут успешно функционировать в национальных границах и заинтересованы в создании глобальных мировых рынков. Благодаря ей многие страны мира в течение последних десятилетий добились

1 USA National Security Strategy. URL: https://ru.scribd.com/doc/261534529/2015-USA-NationalSecurity-Strategy (accessed 28.04.2018).

2 National Security Strategy of the United States of America. December 2017. URL: https://news.usni. org/2017/12/18/document-national-security-united-states-of-america (accessed 28.04.2018). 
значительных экономических успехов. Но она же несет для государств немало негативных последствий, что вызывает во многих странах желание ограничить ее распространение, поставить под контроль государства ее различные проявления [Савио 2018]. По этой причине в ближайшем будущем будет продолжаться торможение глобализации, нахождение ее новых форм проявления, позволяющих снизить ее издержки. Таким образом, глобализация носит не линейный, а циклический характер. Поэтому говорить о том, что эпоха глобализации подходит к концу, преждевременно [Hammes 2016]. Остановить ее невозможно в силу ее объективного характера. Как сказал председатель КНР Си Цзиньпин, «нравится это Вам или нет, глобальная экономика - это большой океан, от которого вы не можете убежать. Любая попытка перекрыть поток капитала, технологий, продуктов, отраслей и людей между экономиками и направлять воды океана в изолированные озера, каналы просто невозможна» ${ }^{1}$.

Новой тенденцией мирового развития является создание крупных экономических мегапартнерств, в которых объединены государства, расположенные на разных континентах. То есть, речь идет о трансрегиональном сотрудничестве. В основе трансрегионализма в отличие от регионализма лежит не территориальная близость и общие границы, а согласованность экономических интересов государств. Согласованные экономические интересы, оформленные в виде соответствующих межгосударственных договоренностей, определяют эффективность такого взаимодействия, а географическая близость в условиях развития современной транспортной инфраструктуры теряет свою экономическую роль и отходит на второй план. На крупные трансрегиональные мегапартнерства приходится значительная часть мировой экономики, мировой торговли и инвестиций. В них для участников устанавливается особый преференциальный режим. С учетом вхождения в разные союзы одних и тех же стран удельный вес некоторых мегапартнерств в мировом ВВП составляет $30-40 \%$, в мировом экспорте товаров и услуг - 25-45\%, в накопленных ПИИ - 20-40\% [Хейфец 2018]. Так, 12 стран: Австралия, Бруней, Вьетнам, Канада, Малайзия, Мексика, Новая Зеландия, Перу, Сингапур, США, Чили, Япония подписали Соглашение о Транстихоокеанском партнерстве (ТТП). После выхода из него США оставшиеся 11 государств в ноябре 2017 г. на саммите АТЭС во Вьетнаме подписали Всеобъемлющее и прогрессивное соглашение для Транстихоокеанского партнерства. В 2016 г. вступило в силу соглашение между ЕС и Канадой - Всеобъемлющее экономическое и торговое соглашение CETA. Оно является новой формой сотрудничества Евросоюза с третьими странами в виде соглашений о создании глубокой и всесторонней зоны свободной торговли. Чуть ранее, в декабре 2015 г., ЕС подписал соглашение о формировании ЗСТ с Вьетнамом. В декабре 2017 г. успешно завершились переговоры с Японией о создании ЗСТ. В настоящий момент завершаются переговоры по созданию Регионального всеобъемлющего экономического партнерства между 10 странами АСЕАН и Китаем, Японией, Индией, Республикой Корея, Австралией и Новой Зеландией. Существуют и другие мегарегиональные проекты, которые либо уже действуют, либо находятся в стадии оформления. Это соглашение о зоне свободной торговли между США и Индией, Евразийский экономический союз, зона свободной торговли СНГ, Общий рынок Восточной и Южной Африки и др. Россия также предлагает свои мегапроекты. Наиболее значительным из них является проект сотрудничества в Большой Евразии. На саммите Россия - ACЕАН, который состоялся в ноябре 2018 г. в Сингапуре,

\footnotetext{
1 Xi Jinping. Keynote at the World Economic Forum Davos. 17 January. 2017. URL: https://america.cgtn. com/2017/01/17/full-text-of-xi-jinping-keynote-at-the-world-economic-forum (accessed 18.05. 2018).
} 
был подписан меморандум о взаимопонимании между АСЕАН и Евразийским экономическим союзом, который предусматривает создание зоны свободной торговли между ЕврАзЭс и всеми странами региона. В рамках этих трансрегиональных группировок предусматривается ликвидация почти всех импортных пошлин и нетарифных барьеров, существенно либерализируется межгосударственная торговля услугами и трансграничное перемещение инвестиций. Это ведет к возникновению особо благоприятных условий для ускоренного развития экономических связей участников подобных мегапроектов. Но для стран, не входящих в подобные образования, создаются неравные условия конкуренции.

Таким образом, происходит серьезное переформатирование глобальной экономики, что имеет также и свои геополитические последствия. Трансрегионализация не тормозит и тем более не отменяет глобализацию, а, напротив, способствует ее дальнейшему развитию. Геополитическое измерение трансрегионализации проявляется в возрастании взаимозависимости экономического и социального развития стран-членов, во включении в производственные цепочки не только на региональном, но и на трансрегиональном уровне.

Особенностью нынешнего этапа глобализации, наряду с цифровыми и другими современными технологиями, является возрастающая роль неформальных связей. Речь идет о контактах между людьми, некоммерческими организациями, муниципальными организациями и т.д. Складывается интеграция «снизу», которая не требует межгосударственного согласования, создания специальных надгосударственных институтов. Она базируется на экономических интересах, инициативе акторов рынка, неформальных связях. Драйвером неформальной глобализации «снизу» выступает потребительская глобализация. О масштабах международных связей «снизу» говорят следующие данные. В 2016 г. международные поездки совершили 1,2 трлн чел., 361 млн чел. сделали покупки за рубежом по каналам интернет-торговли, 244 млн чел. жили в странах, гражданами которых они не являются, число пользователей социальных сетей, у которых был, по крайней мере, один иностранный «друг», составило 914 млн чел., 44 млн чел. работали on-line за рубежом, 13 млн студентов обучались on-line и 5 млн - непосредственно в зарубежных университетах ${ }^{1}$. По словам известного российского экономиста Б. Хейфеца, «именно развитие подобных неформальных потребительских связей станет основой для дальнейшего прогресса глобализации в мировой экономике. Главной особенностью данного этапа будет постепенный переход от глобализации производства к глобализации потребления» [Хейфец 2018: 34].

Перестройка сложившихся глобальных производственных цепочек предоставляет РФ значительные шансы для эффективного включения в международное разделение труда на основе использования достижений технологий четвертой промышленной революции и новых форм глобализации. Однако обостряющийся конфликт с Западом создает серьезные препятствия на этом пути. Санкционная политика США и ЕС вынуждает Россию делать ставку на собственные возможности, сокращать кооперационные связи с мировыми производителями высокотехнологичных изделий, создавать производственные мощности для их производства внутри страны.

Как заявляет В. Сурков, и его слова отражают настроения значительной части российского общества и политического истеблишмента, завершается период «эпического путешествия России на Запад», прекращаются многократные

${ }^{1}$ European Commission (2017). Reflection Paper on Harnessing Globalization. 10 May. P. 7; UNCTAD (2017) Digitalization, Trade and Development. Information Economy Report. P. 16. 
и бесплодные попытки «стать частью западной цивилизации, породниться с “хорошей семьей” европейских народов». По его словам, России «предстоит сто (двести? триста?) лет геополитического одиночества» [Сурков 2018]. Иными словами, России следует настроиться на длительную конфронтацию с Западом, что отнюдь не исключает сотрудничество, в т.ч. и в области экономики.

Сегодня сложилась такая ситуация, когда во взаимосвязанном глобальном социуме политические решения, затрагивающие интересы государств и народов всего мира, принимаются и осуществляются в основном странами Запада во главе с США. Они присвоили себе право от имени мирового сообщества переформатировать экономическую и политическую карту мира, что не может не вызывать возражений или сопротивления со стороны других стран, в т.ч. и России. Тем самым возникает противоречие между глобальностью охвата мировой политики и партикулярностью подходов к ее выработке и реализации. Это реально существующее противоречие не является лишь результатом попыток США и их союзников использовать свое экономическое и военное преимущество для достижения собственных геополитических и геоэкономических целей. Суть этого противоречия заключается в том, что пока еще не имеется таких правовых механизмов регулирования, которые были бы адекватны условиям функционирования глобальных процессов на рынке труда, товаров, услуг, т.е. складывающейся единой мировой экономики. Нельзя не видеть, что они формируются, но намного медленнее, чем образуется глобальная экономика.

По существу, это противоречие является частью более общей проблемы, стоящей сегодня перед человечеством, - необходимостью создания системы глобального регулирования и управления и невозможностью ее создания в обозримом будущем. Действующие институты глобального управления в лице ООН, $G-7, G-20$, Международного валютного фонда, Международного банка реконструкции и развития не обладают необходимыми механизмами исполнения принимаемых решений, что делает проведение общей согласованной политики делом практически невозможным. Следует также учитывать, что многие политические и экономические процессы в мире развиваются помимо воли государств, что только усиливает непредсказуемость и хаотичность современного мира. Все более ощутимая потребность в глобальном управлении мировыми политическими и экономическими процессами, что предполагает существенное ограничение государственного суверенитета, установление контроля над деятельностью негосударственных акторов мировой политики и невозможность создания эффективно действующего института глобального управления, т.к. все акторы мировой политики стремятся всеми путями и средствами сохранить свой суверенитет и независимость, представляет собой одно из важнейших противоречий современности.

В современном мире все более значимую роль играют транснациональные корпорации и глобальные компании. Обладая гигантскими финансово-экономическими и политическими ресурсами, зачастую превосходящими аналогичные ресурсы национальных государств, они являются основным противником национального государства и стремятся размыть его суверенитет, с тем чтобы оно не мешало им обеспечивать свои интересы. Их деятельность ведет к нарастанию конфликтности и неустойчивости обстановки в различных регионах мира [Колодко 2014].

Глобальные компании и транснациональные корпорации постепенно становятся такими же субъектами мировой политики, как и национальные государства, присваивая себе многие их функции и характеристики. Наметившаяся в международных отношениях устойчивая тенденция по размыванию принци- 
пов международного права, и в первую очередь принципа невмешательства во внутренние дела государств, уважения территориальной целостности, государственного суверенитета, отвечает их интересам, т.к. тем самым ослабляется влияние их главного конкурента - национального государства.

Но национальное государство еще не исчерпало себя, не растратило свой потенциал и в состоянии оказывать сопротивление всем попыткам подорвать его позиции. Оно еще долго будет оставаться краеугольным камнем мирового порядка, но борьба сторонников и противников национального государства в предстоящие десятилетия будет определять процесс строительства нового мирового порядка. В этой связи оправданно говорить о том, что основным камнем преткновения на пути установления нового мирового порядка будет являться национальное государство, действующее на основе принципа уважения суверенитета и невмешательства во внутренние дела, территориальной целостности. Наступление на государственный суверенитет во многом определяет и будет определять содержание мировой политики и международных отношений в будущем.

Современные тенденции развития мироустройства свидетельствуют о его растущей дестабилизации, и пока что не видно даже намеков на возможность достижения стабильности хотя бы в среднесрочной перспективе. Человечество вступило в новую эпоху своей непрекращающейся эволюции. Каждый раз, когда оно вступало в такую эпоху, начиналась полоса войн и социальных потрясений, политической неустойчивости прежде чем удавалось установить контроль над всей системой отношений, отражающих новый уровень взаимоотношений между людьми, социальными группами и государствами. Новые тенденции, отражающие потребности экономики, прорубали себе дорогу в исторической толще событий с помощью кровавой борьбы и насилия как повивальной бабки прогресса. И сегодня принципы организации нового мирового порядка утверждаются с помощью насилия. Сила еще долго будет оставаться важнейшим средством достижения стратегических целей в руках стран и межгосударственных объединений.

В условиях становления нового мирового порядка Россия, отбросив всякие колебания, активно включилась в переустройство мира, с тем чтобы его форматирование в максимально возможной степени отвечало ее интересам. Ее активные действия в этом направлении расшатывают сложившийся мировой порядок, представляют прямой вызов его главным выгодополучателям - Западу и в первую очередь США. Но ее положение, которое она занимает среди великих держав, является уязвимым. Разрыв между политическими амбициями страны и имеющимися материальными возможностями определяет противоречивость ее внешней политики, выражающейся в метаниях между Западом и Востоком, в различных комбинациях отношений с ними, с тем чтобы утвердить свою самостоятельность в мире.

\section{Список литературы}

Колодко Г. 2014. Куда идет мир. Политическая экономия будущего. М.: Магистр. $440 \mathrm{c.}$

Кузык Б.Н., Титаренко М.Л. 2006. Китай - Россия-2050: стратегия соразвития. М.: Институт экономических стратегий. 656 с.

Савио Р. 2018. Миллиардеры, финансовый рай, мировой долг и жертвы. Мир перемен. № 1. С. 121-132.

Сурков В. 2018. Одиночество полукровки. (14+). - Россия в глобальной политике. Доступ: https://globalaffairs.ru/global-processes/Odinochestvopolukrovki-14-19477 (проверено 28.12.2018). 
Хейфец Б. 2018. Метаморфоза экономической глобализации. М.: Изд-во ИЭ РАН. 42 c.

Brzezinski Z. 2009. The Group of Two that Could Change the World. - Financial Times. 13.01. URL://http://www.ft.com/cms/s/0/d99369b8-e178-11dd-afa00000779fd2ac.html?nclick_check=1 (accessed 18.05.2018).

Hammes T. 2016. The End of Globalization? The International Security Implications. URL: https://warontherocks.com/2016/08/the-end-of-globalization-the-international-implications (accessed 16.01.2019).

SHEREMET'EV Denis Vital'evich, postgraduate student at the Institute of Europe, Russian Academy of Sciences (bld. 3, 11 Sadovaya-Samotechnaya St, Moscow, Russia, 125009), Senior Lecturer at the Chair of Management, Service and Tourism, Institute of International Social and Humanitarian Relations (bld. 1, 6 Antonova-Ovseenko St, Moscow, Russia, 123100; den.sheremetiev@yandex.ru)

\title{
MEGATRENDS IN THE DEVELOPMENT OF THE MODERN WORLD SYSTEM AND THE SECURITY INTERESTS OF RUSSIA
}

\begin{abstract}
The article examines the main characteristics of the emerging new system of international relations, highlights the megatrends that determine its formation. The author notes that although the United States influence on world political and economic processes is decreasing, they still remain the key factor in world politics and the world economy and will retain those positions in the foreseeable future. World history shows that international relations have always striven to bipolarity and there is no reason to deny their modern evolution in the same direction. World policy is implemented in the context of globalization, which remains the main megatrend in the development of the modern world. The current stage of globalization urgently calls for the formation of effective system of global governance, which implies rejection of existing rules of international law, a state's failure on its own sovereignty. At this stage of the evolution of human civilization, the establishment of a world government is impossible. The resulting contradiction between the objective need for global governance and the impossibility of its implementation is one of the most important megatrends of our time, determining the course of the world political process.

It is very important to Russia to fit into these megatrends, find their niche and use them in the interests of their own modernization in order to avoid marginalization.
\end{abstract}

Keywords: megatrends, globalization, trans-regionalization, power, law, global governance, sovereignty, bipolarity 